\title{
Central venous catheter-associated bloodstream infections occurring in Canadian intensive care units: A six-month cohort study
}

\author{
Donna Holton MD, Shirley Paton MN RN ${ }^{1}$, John Conly $M D^{2 *}$, Joanne Embree $\mathrm{MD}^{3}$, Geoffrey Taylor $\mathrm{MD}^{4}$, \\ William Thompson $\mathrm{MD}^{5+}$, Canadian Nosocomial Infection Surveillance Program ${ }^{\ddagger}$
}

D Holton, S Paton, J Conly, J Embree, G Taylor, W Thompson, Canadian Nosocomial Infection Surveillance Program. Central venous catheter-associated bloodstream infections occurring in Canadian intensive care units: A six-month cohort study. Can J Infect Dis Med Microbiol 2006;17(3):169-176.

OBJECTIVE: To determine the rate and risk factors associated with central venous catheter (CVC)-associated bloodstream infections (BSIs) in Canadian intensive care units (ICUs).

DESIGN: A prospective, active six-month cohort with a nested case-control study.

SETTING: Forty-one ICUs located in 19 Canadian hospitals. METHODS: Data were collected using a standardized format on all CVCs and patients when a CVC was inserted for more than $48 \mathrm{~h}$. Results of microbiological studies and therapeutic interventions were recorded when a BSI occurred.

RESULTS: There were 182 BSIs from 3696 CVC insertions in 2531 patients. Coagulase-negative staphylococci were responsible for $73 \%$ of the BSIs. Mean rates of CVC-associated BSIs per $1000 \mathrm{CVC}$ days were 6.9, 6.8 and 5.0 in adult, neonatal and pediatric ICUs, respectively. Significant factors associated with BSI included duration of CVC insertion $(\mathrm{OR}=1.2,95 \% \mathrm{CI} 1.1$ to 1.3$)$, receiving total parenteral nutrition $(\mathrm{OR}=4.1,95 \% \mathrm{CI} 1.2$ to 14.3$)$ and having one or more CVCs $(\mathrm{OR}=3.1,95 \% \mathrm{CI} 1.5$ to 6.5$)$. In the case-control study, $80 \%$ of the variance in a backward elimination logistic regression analysis was explained by duration of $\mathrm{CVC}$ insertion ( $\mathrm{OR}=1.2$ per day), receiving chemotherapy $(\mathrm{OR}=6.1)$, more than one $\mathrm{CVC}$ insertion during the study $(\mathrm{OR}=3.5)$, insertion of a CVC with two or more lumens $(\mathrm{OR}=2.3)$, using the $\mathrm{CVC}$ to administer total parenteral nutrition $(\mathrm{OR}=1.6)$ and having a surgical wound other than a clean wound $(\mathrm{OR}=1.6)$.

CONCLUSION: The present study identified risk factors explaining $80 \%$ of the variance associated with BSIs and is one of the largest reports on the rate of CVC-associated BSIs occurring in the ICU setting.

Key Words: Bacteremia; Central venous catheter; Intensive care unit; Risk factor

\section{Infections hématogènes liées aux cathéters veineux centraux dans des services de soins intensifs au Canada : étude de cohortes, d'une durée de six mois}

BUT : L'étude avait pour but de déterminer les taux d'infections hématogènes $(\mathrm{IH})$ liées aux cathéters veineux centraux (CVC) dans des services de soins intensifs (SSI) au Canada, ainsi que les facteurs de risque. PLAN D'ÉTUDE : Il s'agit d'une étude prospective de cohortes, avec traitement actif, d'une durée de six mois, assortie d'une étude malades/témoins.

LIEU : L'étude a été menée dans 41 services de soins intensifs, dans 19 hôpitaux, au Canada.

MÉTHODE : Il y a eu collecte de données sur les CVC et les patients chaque fois qu'un tube était posé pour une période de plus de 48 heures, et ce, à l'aide d'un formulaire uniformisé. Les résultats des analyses microbiologiques et des interventions thérapeutiques étaient consignés dans les cas où se produisait une infection hématogène.

RÉSULTATS : Nous avons relevé 182 infections hématogènes sur 3696 poses de CVC chez 2531 patients. Les staphylocoques à coagulase négative ont été mis en cause dans $73 \%$ des infections. Les taux moyens d'IH associées aux CVC se sont établis à 6,9; 6,8 et 5,0 chez les adultes, les nouveau-nés et les enfants admis aux SSI, respectivement, pour 1000 jours-CVC. Parmi les principaux facteurs associés aux IH figuraient le temps de port du CVC (risque relatif approché [RRA]=1,2; intervalle de confiance [IC] à $95 \%: 1,1-1,3)$, la nutrition parentérale totale (RRA =4,1; IC à $95 \%: 1,2-14,3$ ) et le fait d'avoir un ou plusieurs CVC (RRA =3,1; IC à $95 \%: 1,5-6,5)$. Dans l'étude malades/témoins, le temps de port du CVC (RRA=1,2 par jour), la chimiothérapie (RRA=6,1), la pose d'au moins deux CVC au cours de l'étude (RRA=3,5), la pose de cathéters à deux lumières ou plus $(\mathrm{RRA}=2,3)$, la nutrition parentérale totale par le CVC $(\mathrm{RRA}=1,6)$ et une plaie opératoire souillée ( $R R A=1,6)$ expliquaient $80 \%$ de la variance dans l'analyse de régression logistique d'élimination rétrograde.

CONCLUSIONS : La présente étude a permis de cerner les facteurs de risque expliquant $80 \%$ de la variance associée aux infections hématogènes et est l'une des principales études faisant état de taux d'IH liées aux CVC dans les SSI.

${ }^{1}$ Public Health Agency of Canada, Ottawa; ${ }^{2}$ University Health Network, Toronto, Ontario; ${ }^{3}$ Health Sciences Centre, Winnipeg, Manitoba;

${ }^{4}$ University of Alberta Hospital, Edmonton, Alberta; ${ }^{5}$ Moncton Hospital, Moncton, New Brunswick

* Presently at the Calgary Health Region, Calgary, Alberta; ${ }^{\dagger}$ Presently at the London Health Sciences Centre, London, Ontario

*A complete list of all Canadian Hospital Epidemiology Committee members can be found in the appendix

Correspondence: Central Venous Line Working Group (J Conly, G Taylor, J Embree, W Thompson, S Paton), Division of Nosocomial and

Occupational Infections, Bureau of Infectious Diseases, Centre for Infectious Disease Prevention and Control, Population and Public Health Branch,

Public Health Agency of Canada, Health Canada, Address Locator O603E1, Tunney's Pasture, Ottawa, Ontario K1A OL2.

Telephone 613-957-0326, fax 613-998-6413, e-mail Shirley_Paton@phac-aspc.gc.ca

Received and accepted for publication April 3, 2006 
$\mathrm{T}_{1}^{\mathrm{h}}$ he use of central venous catheters (CVCs) has permitted life-saving treatment for individuals requiring hemodynamic monitoring, total parenteral nutrition (TPN), emergency hemodialysis or chemotherapy. However, CVCs are also associated with significant and sometimes life-threatening infectious complications such as septicemia and septic thrombophlebitis (1-7). The National Nosocomial Infection Surveillance System (NNIS) in the United States has reported that most nosocomial bloodstream infections (BSIs) in intensive care units (ICUs) are associated with indwelling intravascular devices (6). Although there is debate in the literature on the confounding variable of severity of underlying illness, reports suggest up to a $35 \%$ increase in attributable mortality in hospitalized patients with a CVC-associated BSI $(1,2)$. Health Canada has recommended that all health care facilities calculate their rate of CVC-associated BSIs to allow comparisons with the infection rates reported in other health care facilities, within their own facility over time and within the literature (8), acknowledging the limitations of interhospital comparisons $(2,3,9,10)$.

Little is known about the rate of CVC-associated BSIs occurring in Canada. Therefore, the Canadian Nosocomial Infection Surveillance Program (CNISP) - a collaboration between the Centre for Infectious Diseases Prevention and Control within the Public Health Agency of Canada (formerly the Laboratory Centre for Disease Control, Health Canada) and the Canadian Hospital Epidemiology Committee - a subcommittee of the Association of Medical Microbiology and Infectious Diseases Canada (formerly the Canadian Infectious Disease Society) - conducted a prospective six-month cohort study in Canadian Hospital Epidemiology Committee member health care facilities, using standardized definitions and methodology to determine the rates of BSIs occurring in patients in Canadian ICUs. Potential risk factors for CVCassociated BSIs were simultaneously evaluated in a nested case-control study.

\section{METHODS}

\section{Prestudy questionnaire and pilot study}

A prestudy questionnaire sent to 21 Canadian health care facilities participating in the CNISP revealed the use of at least four different sets of criteria for defining catheter-related BSIs; furthermore, it was found that not all facilities calculated CVC-associated BSI rates (11). Responders from these sites also stated that CVCs inserted for less than $48 \mathrm{~h}$ rarely became infected, and expressed concern that enrolling all CVCs was not time effective. A one-month, prospective pilot study (12) conducted in four sites (14 ICUs) was performed to determine the feasibility of enrolling only CVCs inserted for more than $48 \mathrm{~h}$ and to test the questionnaire. During the pilot study, only $14 \%$ of all CVCs inserted were in place for more than $48 \mathrm{~h}$. No CVC inserted for less than $48 \mathrm{~h}$ became infected. The design of the six-month cohort study was based on the information gained from the prestudy questionnaire and the pilot study. Thus, based on the pilot test questionnaire, the researchers decided to only enroll CVCs that had been inserted for more than $48 \mathrm{~h}$.

\section{Enrollment and data collection for the prospective cohort study}

The study was conducted as part of routine, active surveillance activities in participating CNISP site ICUs. All ICU patients who had a catheter greater than $5 \mathrm{~cm}$ in length inserted into a central vein (eg, internal jugular, external jugular or subclavian), a peripheral vein (arm, femoral, umbilical or other peripheral vein) or an umbilical artery were eligible for enrollment provided the following criteria were met: CVCs were inserted for more than $48 \mathrm{~h}$ during the surveillance period; they were left in situ for 30 days or less; CVCs were inserted in the ICU or in the $24 \mathrm{~h}$ before ICU admission. CVCs with an attachable cuff were eligible for enrollment but midline catheters and pulmonary artery catheters were not. Patients with cuffed, tunnelled catheters or implanted catheters were not enrolled unless the devices were inserted in a child younger than one year of age and met all other enrollment criteria eligible for enrollment. Both newly inserted CVCs and CVCs replaced over a guidewire were eligible. If a patient had more than one CVC inserted during the surveillance period, each CVC inserted that met the inclusion criteria was enrolled. All CVCs were enrolled using a unique coding system to protect patient confidentiality.

The CVC-associated BSIs were classified as definite, probable or possible (Table 1 ) according to the criteria published by Health Canada (8). Blood and CVC exit site cultures were performed while the patient was in the ICU. Catheter tip cultures were performed using the semiquantitative method described by Maki et al (13). When calculating the CVC-associated rates of BSIs, CVCs were counted only once as the source of infection.

Data collected for each CVC inserted included the following: date of insertion, date of removal or date of patient transfer from the ICU, insertion site, insertion complications, use of a CVC impregnated with an antibiotic or antiseptic agent, the number of lumens, the presence or absence of a cuff, the use of needles to enter the administrative tubing system, primary use of the CVC, reasons why the CVC was removed and whether the CVC was replaced, date of birth, and reason for the patient's ICU admission. Birth weight was recorded when a CVC patient was enrolled in a neonatal ICU. For all CVCs associated with a BSI, results of blood cultures, CVC tip cultures, the presence or absence of septic thrombophlebitis, the presence of a CVC exit site or tunnel infection, corresponding laboratory data, action taken in response to the BSI (ie, use of antimicrobial agents and/or removal of the CVC) and patient outcome were collected.

Catheter days were defined as the end date minus insertion date or the date the patient was transferred from the unit, and patient enrollment days were defined as the end date of the last CVC inserted into the patient minus the date the first catheter was inserted. The duration of enrollment was determined for each patient and used to calculate a pooled mean and median length of enrollment for each ICU. This value was used as a surrogate marker for patient care acuity based on the premise that longer patient enrollments would be reported in more seriously ill patients.

Criteria and data collection for the nested case-control study Individuals with a CVC-associated BSI were age-matched (younger than one year of age, one to 18 years of age and older than 18 years of age) and unit-matched (same ICU) with the first individual enrolled after the individual who did not have a BSI. If a control patient was not identified by the end of the study using the above criteria, the control patient was identified as the first individual enrolled before the individual who was in the same ICU, who did not have a BSI and who met the age-match criteria. Additional data collected for the cases and controls included immune status (presented with diabetes mellitus; infected with HIV; treated with chemotherapy, radiotherapy or high-dose steroids equivalent to prednisone $2.0 \mathrm{mg} / \mathrm{kg} / \mathrm{day}$ or greater in 
TABLE 1

Definitions of intravascular device-associated infections - Local infection, tunnel or pocket infection and bacteremia

\begin{tabular}{|c|c|c|c|}
\hline Definition & Definite & Probable & Possible \\
\hline Local infection & $\begin{array}{l}\text { Purulent discharge at exit site; or erythema } \\
\text { tenderness, induration (two of three) at exit site } \\
\text { with a positive culture of serous discharge }\end{array}$ & $\begin{array}{l}\text { Erythema, tenderness, induration (two of three) } \\
\text { at exit site without a positive culture of } \\
\text { serous discharge; or above without } \\
\text { discharge but lack of alternative explanation }\end{array}$ & $\begin{array}{l}\text { Erythema, tenderness, induration } \\
\text { (two of three) at exit site, but } \\
\text { alternative cause cannot be } \\
\text { ruled out }\end{array}$ \\
\hline $\begin{array}{l}\text { Tunnel or pocket } \\
\text { infection (for } \\
\text { tunnelled and } \\
\text { totally implanted } \\
\text { devices) }\end{array}$ & $\begin{array}{l}\text { Purulent discharge or aspirate from a tunnel or } \\
\text { pocket site not contiguous with exit site; or } \\
\text { erythema, tenderness, induration (two of three) at } \\
\text { a tunnel or pocket site not contiguous with exit } \\
\text { site with a positive culture of serous discharge } \\
\text { or aspirate from that site }\end{array}$ & $\begin{array}{l}\text { Erythema, tenderness, induration (two of three) } \\
\text { at a tunnel or pocket site not contiguous } \\
\text { with exit site and serous discharge or } \\
\text { aspirate from that site without a positive } \\
\text { culture; or above without discharge but lack } \\
\text { of alternative explanation }\end{array}$ & $\begin{array}{l}\text { Erythema, tenderness, induration } \\
\text { (two of three) at a tunnel or pocket } \\
\text { site not contiguous with exit site, } \\
\text { but alternative cause cannot be } \\
\text { ruled out }\end{array}$ \\
\hline $\begin{array}{c}\text { Device-related } \\
\text { bacteremia }\end{array}$ & $\begin{array}{l}\text { Confirmation of septic thrombophlebitis with a } \\
\text { single positive blood culture; or single positive } \\
\text { blood culture and positive culture of catheter } \\
\text { segment with identical organism; or } 10 \text {-fold or } \\
\text { greater colony count difference in blood cultures } \\
\text { drawn from device and peripheral blood; or } \\
\text { single positive blood culture and positive culture } \\
\text { from discharge or aspirate from exit site, tunnel or } \\
\text { pocket with identical organism }\end{array}$ & $\begin{array}{l}\text { Two or more positive blood cultures with no } \\
\text { evidence for source other than the device; } \\
\text { or single positive blood culture for } \\
\text { Staphylococcus aureus or Candida species } \\
\text { with no evidence for source other than device; } \\
\text { or single positive blood culture for coagulase- } \\
\text { negative staphylococci Bacillus species, } \\
\text { Corynebacterium jeikeium, Enterococcus species, } \\
\text { Trichophyton species or Malassezia species in } \\
\text { immunocompromised or neutropenic host species } \\
\text { or in patients receiving total parenteral nutrition } \\
\text { with no evidence for source other than a } \\
\text { centrally placed device }\end{array}$ & $\begin{array}{l}\text { Single positive blood culture with } \\
\text { no evidence for source except a } \\
\text { centrally placed device, and } \\
\text { patient or organism does not fit } \\
\text { criteria for probable } \\
\text { es }\end{array}$ \\
\hline
\end{tabular}

children, or $20 \mathrm{mg} /$ day or greater in adults; or, organ transplant recipients), presence or absence of a surgical wound, presence of a tracheostomy, use of endotracheal intubation, white blood cell (WBC) count and serum albumin level. For case and control CVCs, the time of insertion, the physical location where the CVC was inserted and whether the CVC was inserted as an elective or emergency procedure were reported.

Age-specific criteria were used to classify WBC counts and serum albumin levels into categorical variables. The serum albumin level was classified as low when the level was less than $26 \mathrm{~g} / \mathrm{L}$ in individuals younger than eight weeks of age, less than $34 \mathrm{~g} / \mathrm{L}$ in individuals between eight weeks and three years of age, and less than $39 \mathrm{~g} / \mathrm{L}$ in individuals over three years of age. The complete questionnaire and in-depth variable definitions are available from the CVC Working Group, CNISP, Public Health Agency of Canada.

\section{Analysis}

Data were entered and analyzed using EPI INFO 6.04b (Centers for Disease Control and Prevention, USA) and SAS (SAS Institute Inc, USA). Categorical data were analyzed for significance with the $\chi^{2}$ test, using either Yates correction or a Fisher's exact test as appropriate. The $\chi^{2}$ test for linear trends was used to assess the risk of infection related to the number of CVCs enrolled per patient. Means were analyzed using a Kruskal-Wallis $\mathrm{H}$ test because the data were not normally distributed. Spearman's rank correlation was used to test for any relationship between variables. $\mathrm{P}<0.05$ was considered significant. Risk factors identified in the univariate analysis that had an $\mathrm{OR}$ greater than 2.0 or $\mathrm{P}<0.05$ were included in a multiple logistic regression analysis. Analysis was performed using all CVCs enrolled in the study and repeated analysis used patients rather than CVCs as the basis of the
TABLE 2

Rates (mean [range]) of CVC-related bacteremia by type of intensive care unit (ICU) and denominator

\begin{tabular}{lccc}
\hline Denominator & Neonatal ICUs & Pediatric ICUs & Adult ICUs \\
\hline 100 CVCs & $6.6(0-14.3)$ & $4.4(0.5-8.8)$ & $4.3(0-16.2)$ \\
$\begin{array}{l}1000 \text { enrollment } \\
\text { days }\end{array}$ & $7.5(0-11.6)$ & $5.6(0.8-11.2)$ & $6.2(0-25.6)$ \\
\begin{tabular}{l}
100 patients \\
\hline
\end{tabular} & $10.7(0-18.8)$ & $5.3(0.7-10.6)$ & $6.0(0-18.0)$ \\
\hline
\end{tabular}

CVC Central venous catheter

analysis. In addition, multiple logistic regression using a backward elimination procedure was performed on the data collected for the case-control study. Only data from the first BSI reported in an individual were entered into the analysis. Variables that did not meet the 0.2 significance level were removed from the model. The analysis was performed using both unmatched and matched data.

Prospective cohort study

The prospective cohort study was conducted over a consecutive six-month period in 41 ICUs located in 19 CNISPassociated health care facilities, representing eight of the 10 provinces in Canada. The rates of CVC-associated BSIs were also calculated for all ICU types (Table 2). Table 3 describes the CVC and patient enrollment data, and Table 4 describes the rates of CVC-associated BSIs calculated for the participating ICUs. The adult, pediatric and neonatal ICUs with longer mean and median enrollment times had higher rates of CVCassociated BSIs (the critical value for a Spearman's rank correlation coefficient was not exceeded). The distribution of insertion sites of the CVCs is reported in Table 5. The overall 
TABLE 3

Demographics of participating intensive care units (ICUs)

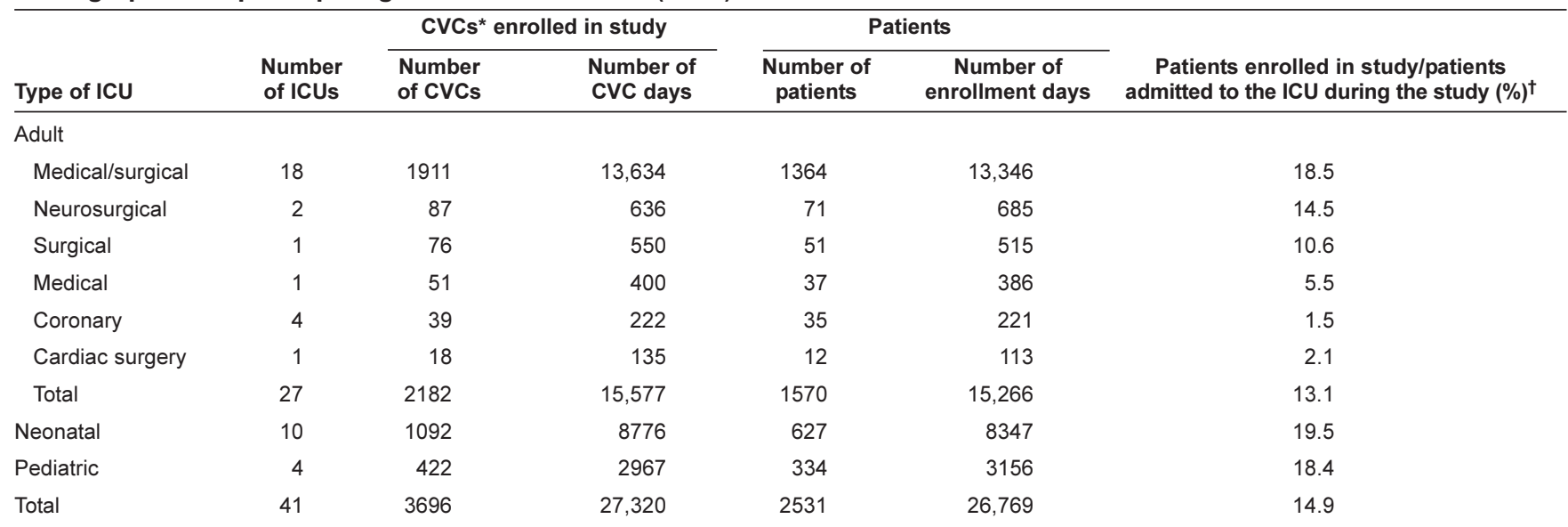

${ }^{*}$ Central venous catheters (CVCs) were used for antimicrobial agent administration (61.8\%), total parenteral nutrition administration (32.9\%) and hemodialysis (5.9\%); 'Data on the number of patients admitted to the ICU during the study were provided by 38 ICUs and were estimated for three ICUs

TABLE 4

Central venous catheter (CVC)-associated rate of bloodstream infections (BSIs)

\begin{tabular}{|c|c|c|c|c|c|}
\hline \multirow[b]{2}{*}{ Type of ICU } & \multirow[b]{2}{*}{$\begin{array}{l}\text { Number } \\
\text { of BSIs }\end{array}$} & \multicolumn{2}{|c|}{ Rate using CVCs } & \multicolumn{2}{|c|}{ Rate using patients } \\
\hline & & $\begin{array}{l}\text { Rate/1000 } \\
\text { CVC days }\end{array}$ & $\begin{array}{c}\text { Rate/100 } \\
\text { CVCs }\end{array}$ & $\begin{array}{c}\text { Rate/1000 } \\
\text { enrollment days }\end{array}$ & $\begin{array}{l}\text { Rate/100 } \\
\text { patients }\end{array}$ \\
\hline Adult & 107 & 6.9 & 4.9 & 7.0 & 6.8 \\
\hline \multicolumn{6}{|l|}{ Neonatal } \\
\hline \multicolumn{6}{|l|}{ Birthweight, g } \\
\hline$<1000$ & 27 & 7.5 & 7.4 & 7.4 & 15.9 \\
\hline $1001-1500$ & 7 & 4.1 & 3.2 & 4.3 & 5.2 \\
\hline $1501-2500$ & 6 & 5.5 & 4.0 & 6.3 & 6.0 \\
\hline$>2500$ & 20 & 8.4 & 5.5 & 9.5 & 9.0 \\
\hline Total & 60 & 6.8 & 5.4 & 7.2 & 9.6 \\
\hline Pediatric & 15 & 5.0 & 3.6 & 4.7 & 4.5 \\
\hline Total & 182 & 6.7 & 4.9 & 6.8 & 7.2 \\
\hline Burn* & 6 & 16.1 & 11.1 & 16.7 & 25.0 \\
\hline
\end{tabular}

*Includes patients admitted to adult, neonatal and pediatric intensive care units (ICUs)

rate of CVC-associated BSI was $4.9 \%$ in the present cohort (Table 4). A single CVC-associated BSI occurred in 168 of 2531 patients $(6.6 \%)$. Fourteen of the 168 patients $(8.3 \%)$ had two or more CVC-associated BSI, for a total of 182 CVCassociated BSI in the present study. Twenty-eight of the 182 CVC-associated BSIs (15.3\%) were classified as definite, $117(64 \%)$ as probable and $37(20 \%)$ as possible infections (8).

Of the 189 organisms identified, coagulase-negative Staphylococcus species accounted for 73\%, Staphylococcus aureus 5.8\%, Enterococcus species 5.3\% and Candida species $5.3 \%$. Gram-negative bacilli were isolated $7.9 \%$ of the time (ie, Pseudomonas species 2.1\%, Klebsiella species $2.1 \%$, Enterobacter species 2.1\%, Escherichia coli $1.1 \%$ and Acinetobacter species $0.5 \%)$. Other organisms identified included viridans Streptococcus group (1.1\%), Corynebacterium species $(1.1 \%)$ and Clostridium species $(0.5 \%)$. A single organism was isolated in the majority $(96 \%)$ of the BSIs. Exit site infections were identified in 10 of 182 CVC-associated BSIs (5.4\%). Two tunnel infections $(1.1 \%)$ and one episode of septic thrombophlebitis $(0.5 \%)$ were reported.
TABLE 5

Sites of insertion of central venous catheters (CVCs)

\begin{tabular}{|c|c|c|c|c|}
\hline \multirow[b]{2}{*}{ Vein } & \multirow{2}{*}{$\begin{array}{c}\begin{array}{c}\text { Adult } \\
(\mathrm{n}=2175)^{\star \dagger}\end{array} \\
\% \text { inserted }\end{array}$} & \multicolumn{2}{|c|}{$\begin{array}{l}\text { Neonatal } \\
(n=1092)^{\ddagger}\end{array}$} & \multirow{2}{*}{$\begin{array}{c}\begin{array}{c}\text { Pediatric } \\
(n=422)^{*}\end{array} \\
\% \text { inserted }\end{array}$} \\
\hline & & $\%$ inserted & $\%$ infected & \\
\hline Subclavian & 39.8 & 2.0 & 13.6 & 12.8 \\
\hline Internal jugular & 34.7 & 4.2 & 10.9 & 46.7 \\
\hline Femoral & 20.6 & 4.9 & 11.3 & 34.1 \\
\hline External jugular & 3.0 & 0.4 & 25.0 & 1.2 \\
\hline Arm & 1.7 & 20.2 & 7.2 & 2.8 \\
\hline Umbilical & $\mathrm{N} / \mathrm{A}$ & 26.7 & 3.4 & 0.7 \\
\hline Umbilical artery & N/A & 32.2 & 0.9 & 0.7 \\
\hline Other & 0.2 & 9.3 & 15.7 & 0.9 \\
\hline
\end{tabular}

${ }^{*}$ Nonsignificant relationship between anatomical location of CVC insertion and blood stream infection (BSI) in the adult and pediatric intensive care units; ${ }^{\dagger}$ Data from seven of the CVCs inserted in adults did not indicate site of insertion; ${ }^{\ddagger}$ Because a significant relationship was found between anatomical insertion site and number of BSIs $\left(\chi^{2}=50.5, P<10^{-8}\right)$, the percentage of the CVCs associated with a BSI is presented. If the umbilical artery and umbilical vein catheters were removed, a nonsignificant relationship was found between insertion site and BSIs. N/A Not available

Duration of insertion was found to be a significant risk factor for a BSI $(\mathrm{P}<0.0001)$. CVCs not associated with a BSI were inserted for a mean of 7.1 days (median six days), while CVCs associated with a BSI were inserted for a mean of 11.6 days (median nine days). A CVC was associated with a BSI in $4.1 \%$ of the first CVCs inserted, $6.1 \%$ of the second CVCs inserted, $8.4 \%$ of the third CVCs inserted, $5.9 \%$ of the fourth CVCs inserted and $12.5 \%$ of the fifth CVCs inserted $\left(\chi^{2}\right.$ for linear trends=12.6, $\left.\mathrm{P}<0.0004\right)$. Intrinsic characteristics of the CVCs were evaluated as risk factors for CVC-associated BSI in a univariate analysis. However, some of the characteristics reflected institutional decisions to purchase certain types of CVCs. For example, six institutions used needles to enter the intravenous tubing, five used a needleless system, and eight used both a needle and a needleless system. A needle was used to enter the tubing system in 142 of 181 CVCs associated with a BSI $(78.5 \%)$ compared with 2407 of 3470 CVCs not associated with a BSI $(69.4 \%)(\mathrm{OR}=1.61,95 \%$ CI 1.13 to 2.33 ; $\mathrm{P}=0.01$ ). Five institutions used both impregnated and nonimpregnated CVCs, while 14 institutions used only nonimpregnated 
CVCs $(\mathrm{P}<0.0001)$. Institutions using both impregnated and nonimpregnated CVCs were more likely to have CVCs associated with BSIs than institutions exclusively using nonimpregnated CVCs $(\mathrm{OR}=1.41,95 \% \mathrm{CI} 1.03$ to $1.95 ; \mathrm{P}=0.03)$. The vast majority ( 569 of 586) of the impregnated catheters were antiseptic-coated rather than antibiotic-coated. Five hundred forty of 3471 nonimpregnated CVCs (15.6\%) were associated with a BSI compared with 46 of 181 impregnated CVCs associated with a BSI (25.4\%) $(\mathrm{OR}=0.54,95 \%$ CI 0.38 to 0.77 ; $\mathrm{P}=0.0006)$, with no difference in the duration of insertion of impregnated versus nonimpregnated CVCs (mean of 7.1 days versus 7.5 days, respectively). Fifty-six of the CVCs associated with a BSI $(30.8 \%)$ had two or more lumens compared with 1257 CVCs not associated with a BSI (36.0\%) (nonsignificant difference). Thirty-five of 1091 CVCs (3.2\%) inserted into neonates had cuffs. Seven cuffed CVCs were associated with a BSI compared with 53 uncuffed CVCs (OR=0.21, 95\% CI 0.09 to 0.55; $\mathrm{P}=0.01)$.

Three hundred eighty-six $(15.3 \%)$ of those enrolled in the study died. Death occurred in $23.8 \%$ of the individuals with a CVC-associated BSI and in $14.6 \%$ of the individuals who did not develop a CVC-associated BSI (OR=1.82, 95\% CI 1.22 to 2.67; $\mathrm{P}<0.002)$. The actions taken in response to a CVCassociated BSI and patient survival are denoted in Table 6. Individuals with CVC-associated BSIs caused by organisms other than coagulase-negative staphylococci were not more likely to die than individuals with coagulase-negative staphylococcal BSIs.

\section{Case-control study}

The findings of the unmatched and matched case-control analysis are reported in Table 7 , and the results are very similar. Although the ages of cases and controls were not significantly different in the adult and pediatric ICUs, controls in the neonatal ICUs (mean age 19.6 days) were significantly younger than the case patients (mean age 30.4 days) (Kruskal-Wallis H test 0.2). The birth weights of cases were not significantly different from controls. Among the cases, 73 (40\%) received TPN, 34 (18.7\%) were immunocompromised, and $29(15.9 \%)$ were both immunocompromised and had received TPN (total 74.6\%). Among the controls, 37 (20.3\%) had received TPN, 35 (19.2\%) were immunocompromised, and $10(5.5 \%)$ were both immunocompromised and received TPN (total 45\%). Cases differed significantly from controls in the proportion of individuals in each group $(\mathrm{P}=0.02)$. Only 12 pairs were discordant with respect to the use of impregnated or nonimpregnated CVCs.

\section{Multiple logistic regression analyses}

Using the multiple logistic regression, two continuous and 13 nominal variables were analyzed. Interactions between the uses of the CVC for administering antimicrobial agents, TPN, tracheostomy, as well as the continuous variables time in the ICU and duration of CVC insertion were tested in all analyses and were not found to be significant. Because the variance explained by the duration of CVC insertion and length of time of enrollment was almost identical, only duration of CVC insertion was used in the analyses. In the prospective cohort, significant factors included duration of insertion $(\mathrm{P}=0.0001)$, TPN administration ( $\mathrm{P}=0.0001)$, use of impregnated catheters $(\mathrm{P}=0.002)$ and use of CVC for antimicrobial agents $(\mathrm{P}=0.05)$.
TABLE 6

Action taken in response to bloodstream infection and patient outcome

\begin{tabular}{|c|c|c|c|c|c|}
\hline \multirow[b]{2}{*}{$\begin{array}{l}\text { Number of CVCs } \\
(n=180)\end{array}$} & \multicolumn{2}{|c|}{$\begin{array}{l}\text { Antimicrobial } \\
\text { agent }(n=139)\end{array}$} & \multicolumn{2}{|c|}{$\begin{array}{l}\text { No antimicrobial } \\
\text { agent given }(n=41)\end{array}$} & \multirow{2}{*}{$\begin{array}{l}\text { Deaths } \\
\text { reported }^{*}, \mathrm{r} \\
\text { (\% total) }\end{array}$} \\
\hline & $\begin{array}{c}n \\
(\% \text { total) }\end{array}$ & $\begin{array}{l}\text { Died, } n \\
\text { (\% total) }\end{array}$ & $\begin{array}{c}n \\
\text { (\% total) }\end{array}$ & $\begin{array}{l}\text { Died, } n \\
\text { (\% total) }\end{array}$ & \\
\hline $\begin{array}{l}\text { Catheter removed } \\
\quad(n=115)\end{array}$ & $\begin{array}{c}90 \\
(50.0)\end{array}$ & $\begin{array}{l}16 / 90 \\
(17.8)\end{array}$ & $\begin{array}{c}25 \\
(13.9)\end{array}$ & $\begin{array}{c}3 / 25 \\
(12.0)\end{array}$ & $\begin{array}{l}19 / 115 \\
(16.5)\end{array}$ \\
\hline $\begin{array}{l}\text { Catheter not } \\
\text { removed }(n=65)\end{array}$ & $\begin{array}{c}49 \\
(27.2)\end{array}$ & $\begin{array}{l}13 / 49 \\
(26.5)\end{array}$ & $\begin{array}{c}16 \\
(8.9)\end{array}$ & $\begin{array}{l}7 / 16 \\
(43.8)\end{array}$ & $\begin{array}{l}20 / 65 \\
(30.8)\end{array}$ \\
\hline Deaths reported ${ }^{\dagger}$ & \multicolumn{2}{|c|}{$29 / 139$} & \multicolumn{2}{|c|}{$10 / 41$} & \\
\hline
\end{tabular}

${ }^{*} \mathrm{OR}$ of dying if central venous catheter (CVC) was not removed compared with CVC removed: $O R=2.25,95 \% \mathrm{Cl} 1.02$ to $4.92 \mathrm{P}=0.04$; † $\mathrm{O}$ of dying if no antimicrobial agents were given compared with antimicrobial agents given: $P=n o t$ significant. OR of dying if no action was taken compared with any action being taken: $O R=3.21,95 \% \mathrm{Cl} 0.93$ to $10.5, P=0.05$

Nonsignificant $\mathrm{P}$ values suggesting a trend were reported for two variables: more than one CVC inserted $(\mathrm{P}=0.07)$ and use of needles to enter the system $(\mathrm{P}=0.09)$.

In the nested case-control study of 168 cases, six variables explained $79.8 \%$ of the variance in the unmatched analysis. The conditional ORs were 1.2 per day of CVC insertion after $48 \mathrm{~h}$ (95\% CI 1.1 to 1.3$), 6.1$ if receiving chemotherapy $(95 \%$ CI 1.5 to 24.8$), 3.5$ if the patient had more than one CVC inserted (95\% CI 1.8 to 6.7) and 2.3 if the CVC had more than one lumen (95\% CI 1.2 to 4.3). TPN (OR=1.6, 95\% CI 0.90 to 2.9) and presence of clean/contaminated, contaminated or dirty surgical wound $(\mathrm{OR}=1.6,95 \% \mathrm{CI} 0.84$ to 3.2$)$ were included in the model even though the 95\% CI crossed 'one'. Three of the six risk factors identified in the unmatched backward multiple logistic regression analyses were significant in the matched case-control backward multiple logistic regression analysis. Significant variables included duration of CVC insertion $(\mathrm{OR}=1.2$ per day of $\mathrm{CVC}$ insertion longer than $48 \mathrm{~h} ; 95 \% \mathrm{CI}$ 1.1 to 1.3$)$, receiving TPN $(\mathrm{OR}=4.1,95 \% \mathrm{CI} 1.2$ to 14.3$)$ and having more than one CVC $(\mathrm{OR}=3.1,95 \% \mathrm{CI} 1.5$ to 6.5$)$.

\section{DISCUSSION}

The present study reports the results of a six-month, active prospective, multicentre cohort study that monitored CVCassociated BSIs in 41 ICUs in 19 Canadian health care facilities (75\% of Canada's medical school-affiliated acute care facilities) and represents one of the largest cohorts of this kind studied in Canada. The present study illustrates the complexity of calculating and comparing rates and risk factors associated with CVCassociated BSIs. For example, some studies (14-16) have included all catheters in the denominator data regardless of duration of insertion, while some included only catheters inserted for more than $48 \mathrm{~h}$. The criterion of including only CVCs inserted for more than $48 \mathrm{~h}$ markedly decreased infection control practitioners' workload and did not significantly affect the detection of BSIs because the CVCs associated with a BSI were in place for a mean of 11.6 days. Choosing the latter definition for the denominator in our study arguably resulted in a more accurate and conservative estimate of the CVCassociated rate of BSIs by excluding the large number of patients who would have had CVCs for monitoring purposes only. 
TABLE 7

Case-control study (all cases included)

\begin{tabular}{|c|c|c|c|c|}
\hline \multirow{2}{*}{ Characteristic } & & \multicolumn{2}{|c|}{ Unmatched, n (\%) } & \multirow{2}{*}{$\begin{array}{l}\text { Matched } \\
\text { Statistical test }\end{array}$} \\
\hline & & Case & Control & \\
\hline \multicolumn{2}{|l|}{$\begin{array}{l}\text { Mean length of time } \\
\text { CVC inserted, days }\end{array}$} & 11.6 & 6.1 & Kruskal-Wallis $\mathrm{H}$ test $73.5, \mathrm{P}<10^{-8}$ \\
\hline \multirow{3}{*}{$\begin{array}{l}\text { Intrinsic CVC } \\
\text { characteristics }\end{array}$} & Needles & $142(78.5)$ & $134(73.6)$ & Not significant \\
\hline & $\geq 2$ versus one lumen & $126(69.2)$ & $111(61.3)$ & Crude $\mathrm{OR}=11.1$, matched $\mathrm{OR}=3.33,95 \% \mathrm{Cl} 1.3$ to $10.1, \mathrm{P}=0.005$ \\
\hline & Not impregnated* & $135(74.6)$ & $139(76.4)$ & Not significant \\
\hline \multirow{3}{*}{ Insertion circumstances } & Midnight $-08: 00$ & $16(8.8)$ & $19(10.4)$ & Not significant \\
\hline & Nonelective & $9(4.9)$ & $12(6.6)$ & Not significant \\
\hline & Due to complication & $9(5.0)$ & $13(7.2)$ & Not significant \\
\hline Removal & $\begin{array}{l}\text { Removed due to } \\
\text { suspected sepsis }\end{array}$ & $80(54.4)$ & $7(5.4)$ & Crude $\mathrm{OR}=370$, matched $\mathrm{OR}=19.3,95 \% \mathrm{Cl} 7.22$ to $72.4, \mathrm{P}<10^{-8}$ \\
\hline \multirow[t]{4}{*}{ Immunosuppressed } & Diabetes & $37(20.3)$ & $23(12.7)$ & Crude $O R=2.49$, matched $O R=1.58$, not significant \\
\hline & Chemotherapy & $11(6.0)$ & $3(1.7)$ & Crude $\mathrm{OR}=13.4$, matched $\mathrm{OR}=3.67,95 \% \mathrm{Cl} 0.97$ to $20.47, \mathrm{P}=0.03$ \\
\hline & Steroids & $33(18.4)$ & $22(12.5)$ & Crude $\mathrm{OR}=4.0$, matched $\mathrm{OR}=2.0,95 \% \mathrm{Cl} 0.93$ to $4.57, \mathrm{P}=0.04$ \\
\hline & Total & $63(34.8)$ & $45(26.9)$ & Not significant \\
\hline $\begin{array}{l}\text { Dirty, contaminated or } \\
\text { clean/contaminated } \\
\text { surgical wound }\end{array}$ & & $48(27.3)$ & $28(15.8)$ & Crude $\mathrm{OR}=5.44$, matched $\mathrm{OR}=2.33,95 \% \mathrm{Cl} 1.24$ to $4.6, \mathrm{P}=0.003$ \\
\hline Tracheostomy & & $21(11.5)$ & $9(4.9)$ & Crude $\mathrm{OR}=6.25$, matched $\mathrm{OR}=2.50,95 \% \mathrm{Cl} 1.05$ to $6.56, \mathrm{P}=0.002$ \\
\hline Intubated & & $143(79.0)$ & $148(81.3)$ & Not significant \\
\hline Patient died & & $40(22.0)$ & $16(8.8)$ & Crude $\mathrm{OR}=11.6$, matched $\mathrm{OR}=3.40,95 \% \mathrm{Cl} 1.64$ to $7.7, \mathrm{P}=0.0002$ \\
\hline
\end{tabular}

${ }^{*}$ Nonimpregnated central venous catheters (CVCs) were inserted for a mean of 9.5 days, compared with impregnated CVCs, which were inserted for a mean of 6.9 days (Kruskal-Wallis $H$ test 6.0)

The CVC-associated BSI rate in our study was determined using four denominators. CVC-associated BSI rates calculated per $100 \mathrm{CVCs}$ consistently gave the lowest infection rate. Rates calculated per 1000 CVC days and per 1000 enrollment days gave almost identical rates. Rates calculated per 100 patients were similar to the rates calculated per 1000 CVC days and per 1000 patient enrollment days in the adult and pediatric ICUs, but was higher than the rates calculated in the neonatal ICU. ICUs with longer mean durations of patient enrollment reported higher rates of CVCassociated BSIs, suggesting that these ICUs treated more seriously ill patients.

Our study calculated CVC-associated BSI rates using standardized definitions, which allowed comparability between sites. However, we recognize that a variety of criteria, all of which influence the numerator, have been used to identify a CVC-associated BSI $(3,10)$. For example, some define a CVCassociated BSI when blood cultures from two different sites grow the same organism and no other obvious source of infection is identified, while others require only one positive blood culture with no obvious source of infection (17-21). We acknowledge the limitation in the present study that the rate of CVC BSIs may have been influenced by the use of a 'possible' definition including a number of coagulase-negative staphylococci from a single blood culture, when in fact, this represented contamination. Exclusion of this latter category from the numerator reveals a CVC BSI rate of 5.3 per 1000 days for the entire cohort. We acknowledge that it is possible that infections in the 'possible' category may have been cases of contamination but this would only be in ICUs with large numbers of neutropenic or immunosuppressed patients in their populations, and the latter was a negligible factor in our study. In addition, we acknowledge that lack of postdischarge follow-up from the ICU may have also missed some cases of CVC-associated BSI.

Other factors that need to be considered when reviewing studies reporting rates of CVC-associated BSIs (18) include different patient populations, the intent of catheter use (22) and the duration of use $(14,23)$. Before the study, we predicted that rates calculated in the present study would be higher than those reported by the NNIS (14) because the NNIS uses all CVCs in the denominator data, regardless of duration. However, the rates of infection reported in our study were comparable or lower than the NNIS reported rates. The NNIS, which uses all catheters, has reported pooled mean rates of BSIs in adult ICUs that vary from 4.5 to 7.2 (1986 to 1997) (14) and 2.9 to 5.9 (1992 to 2001) (1) BSIs per 1000 CVC days, compared with 6.2 reported in our study. However, several factors may offer explanations for the rates of CVCassociated BSIs reported in our study. CVCs that crossed the tricuspid valve were excluded from our study, and these CVCs have been reported to have higher rates of infection than CVCs not crossing a heart valve. Another factor affecting the comparison of rates is that different patient populations may be admitted to American versus Canadian ICUs (eg, relatively fewer gunshot injuries are reported in Canada than in the 
United States). In the pediatric ICUs, our pooled rate of CVC-associated BSIs was 5.0 BSIs per 1000 CVC days compared with rates 7.6 and 8.1 reported by NNIS for two different time periods $(1,14)$. The neonatal BSIs rates calculated by birth weight varied from 3.8 to 11.3 and from 4.8 to 12.6 in the NNIS reports from two time periods $(1,14)$, compared with 4.1 to 8.4 in our study. Birth weight was not a risk factor for CVCassociated BSIs in the case-control study, although age was a risk factor in the unmatched case-control data. The CVCassociated BSI rates reported for burn patients in our study (ie, 16.1 BSIs per 1000 CVCs) were very similar to the rate reported in the NNIS study (ie, 14.6 BSIs per 1000 CVCs) (14). Finally, it is possible that differences in placement, catheter care or dressings may have contributed to the lower rates in our study in the pediatric and neonatal populations.

Previously reported risk factors for the development of CVC-associated BSIs were evaluated in our study. Duration of CVC insertion, use of the CVC to administer TPN and having more than one CVC inserted during the ICU admission were identified as risk factors for CVC-associated BSIs in the univariate-matched case-control and multiple logistic regression analyses. These risk factors were identified in the multiple logistic regression analysis using all CVCs, all patients, and matched and unmatched case-control data. In the backward elimination multiple logistic regression analysis using the unmatched case-control data, a very high percentage of the variance (approximately 80\%) was explained by duration of CVC insertion $(\mathrm{OR}=1.2$ per day), receipt of chemotherapy $(\mathrm{OR}=6.1)$, having more than one CVC inserted during the study $(\mathrm{OR}=3.5)$, inserting a CVC with two or more lumens $(\mathrm{OR}=2.3)$, using the CVC to administer TPN $(\mathrm{OR}=1.6)$ and having a surgical wound other than a clean wound $(\mathrm{OR}=1.6)$.

Risk factors relating to the development of CVC-associated BSIs were identified in analyses other than the backward elimination multiple logistic regression, and may have been confounding factors or associations that did not have sufficient numbers to retain their association in more demanding analysis. Interpreting the results for impregnated CVCs is difficult. The initial finding in the cohort analysis that CVCs impregnated with antimicrobial substances were associated with BSIs was unexpected and differs from other reported literature. One other possible explanation is that the association truly exists and that centres using impregnated CVCs used less stringent techniques and catheter care for these CVCs, believing that there was a protective effect using these catheters. However, it may have been a confounding variable because it did not achieve significance in the matched case-control study, which would be considered a more rigorous analysis. The case-control study identified receiving high-dose steroids and having a tracheostomy as additional risk factors.

Factors not associated with BSIs included the anatomical site of the CVC insertion (when the umbilical catheters were excluded from the analyses), use of the CVC for hemodialysis, WBC counts, serum albumin levels, whether the patient was intubated, time of CVC insertion and circumstance under which the CVC was inserted. Having diabetes mellitus had an OR of 2.5 but was not statistically significant. Death occurred in $15.3 \%$ of the individuals enrolled in the study. Death was more likely to occur in individuals who had a CVC-associated BSI (surveillance and case-control). Among individuals with a CVC-associated BSI, failure to remove a CVC associated with a BSI was associated with death, although it is not clear whether these individuals died because of the BSI or whether a decision had been made to withdraw care.

The number of deaths occurring in individuals with coagulase-negative staphylococcal BSIs was not significantly different from the number of deaths occurring in individuals with infections caused by other organisms. This result most likely reflects the importance of coagulase-negative staphylococci as a pathogen in immunocompromised hosts. Sixty per cent of the individuals in the case-control study were immunocompromised, receiving TPN, or both.

\section{SUMMARY}

The present study has provided a benchmark for ICU CVCassociated infections in Canada and has provided insight into using a novel process for CVC infection surveillance (only tracking CVCs inserted for more than $48 \mathrm{~h}$ ). A denominator of CVCs inserted for more than $48 \mathrm{~h}$ may provide a more efficient means of tracking ICU CVC-associated infections by significantly reducing the amount of time data collectors (eg, infection control practitioners and nurses) spend tracking CVC-associated infections.

\section{APPENDIX \\ Canadian Hospital Epidemiology Committee members (in alphabetical order)}

E Bryce, Vancouver Hospital and Health Sciences Centre, Vancouver, British Columbia; D Gregson, St Joseph's Health Care, London, Ontario; M Gourdeau, Hôpital de l'Enfant-Jésus, Quebec City, Quebec; E Henderson, Peter Lougheed Centre, Calgary, Alberta; M Ishak, Hôtel-Dieu St-Jérôme, St-Jérôme, Quebec; L Johnston, Queen Elizabeth II Health Sciences Centre, Halifax, Nova Scotia; A Kureishi, Foothills Hospital, Calgary, Alberta; A Matlow, The Hospital for Sick Children, Toronto, Ontario; A McGeer, Mount Sinai Hospital, Toronto, Ontario; M Miller, Jewish General Hospital, Montreal, Quebec; D Moore, Montreal Children's Hospital, Montreal, Quebec; L Nicolle, Health Sciences Centre and St Boniface Hospital, Winnipeg, Manitoba; A Simor, Sunnybrook Health Science Centre, Toronto, Ontario; B Tan, Royal University Hospital, Saskatoon, Saskatchewan; D Zoutman, Kingston General Hospital, Kingston, Ontario

ACKNOWLEDGEMENTS: The authors wish to acknowledge the infection control practitioners working at the Canadian Hospital Epidemiology Committee sites who collected the data, Teresa Burnett and Ruth Cole, who entered the data, and Michael Manno, who performed the multiple logistic regression analyses. The project was financially supported by the Centre for Infectious Diseases Prevention and Control, Health Canada (formerly the Laboratory Centre for Disease Control), and Rhone-Poulenc Rorer (currently sanofi-aventis).

\section{REFERENCES}

1. O'Grady NP, Alexander M, Dellinger EP, et al. Guidelines for the prevention of intravascular catheter-related infections. Centers for Disease Prevention and Control. MMWR Recomm Rep 2002;51:1-29.

2. Eggimann P, Sax H, Pittet D. Catheter-related infections. Microbes Infect 2004;6:1033-42.

3. Maki DG, Mermel LA. Infections due to infusion therapy In: Bennet JV, Brachman PS, eds. Hospital Infections. Philadelphia: Lippincott-Raven, 1998:689-724

4. Raad II, Bodey GP. Infectious complications of indwelling vascular catheters. Clin Infect Dis 1992;15:197-208.

5. Lindblad B, Wolff T. Infectious complications of percutaneously inserted central venous catheters. Acta Anaesthesiol Scand 1985;29:587-9. 
6. Centers for Disease Control and Prevention (CDC). Monitoring hospital-acquired infections to promote patient safety - United States, 1990-1999. MMWR Morb Mortal Wkly Rep 2000;49:149-53. (Erratum in 2000;49:189-90).

7. Maki DG. Infections caused by intravascular devices used for infusion therapy: Pathogenesis, prevention, and management. In: Bisno AL, Waldvogel FA, eds. Infections Associated With Indwelling Medical Devices, 2nd edn. Washington, DC: American Society for Microbiology Press, 1994:155-212.

8. Public Health Agency of Canada. Infection control guideline: Preventing infections associated with indwelling intravascular access devices. < http://www.phac-aspc.gc.ca/publicat/ccdrrmtc/97vol23/23s8/iiadinde_e.html $>$ (Version current at November 8, 2002).

9. National Nosocomial Infections Surveillance (NNIS) System. Nosocomial infection rates for interhospital comparison: Limitations and possible solutions. A Report from the National Nosocomial Infections Surveillance (NNIS) System. Infect Control Hosp Epidemiol 1991;12:609-21.

10. The Quality Indicator Study Group. An approach to the evaluation of quality indicators of the outcome of care in hospitalized patients, with a focus on nosocomial infection indicators. The Quality Indicator Study Group. Infect Control Hosp Epidemiol 1995;16:308-16.

11. Holton DL, Paton S, Conly J, Embree J, Taylor G, Thompson W, Canadian Hospital Epidemiology Committee (CHEC), Canadian Nosocomial Infection Surveillance Program (CNISP). Central venous catheter associated blood stream infections in Canadian ICUs: Hospital Profile. 37nd Interscience Conference on Antimicrobial Agents and Chemotherapy. Toronto, Ontario, September 28 to October 1, 1997.

12. Holton DL, Paton S, Conly J, Embree J, Taylor G, Thompson W, Canadian Hospital Epidemiology Committee (CHEC), Canadian Nosocomial Infection Surveillance Program (CNISP). Central venous catheter associated blood stream infections in Canadian ICUs: Pilot Study. 37th Interscience Conference on Antimicrobial Agents and Chemotherapy, Toronto, Ontario, September 28 to October 1, 1997.
13. Maki DG, Weise CE, Sarafin HW. A semiquantitative culture method for identifying intravenous-catheter-related infection. N Engl J Med 1977;296:1305-9.

14. National Nosocomial Infections Surveillance System. National nosocomial infections surveillance (NNIS) report, data summary from October 1986-April 1997, issued May 1997. A report from the NNIS System. Am J Infect Control 1997;25:477-87.

15. Raad I, Darouiche R, Dupuis J, et al. Central venous catheters coated with minocycline and rifampin for the prevention of catheter-related colonization and bloodstream infections. A randomized, doubleblinded trial. The Texas Medical Center Catheter Study Group. Ann Intern Med 1997;127:267-74.

16. Conly JM, Grieves K, Peters B. A prospective randomized study comparing the transparent and dry gauze dressings for central venous catheters. J Infect Dis 1989;159:310-9.

17. Jarvis WR, Edwards JR, Culver DH, et al. Nosocomial infection rates in adult and pediatric intensive care units in the United States. National Nosocomial Infections Surveillance System. Am J Med 1991;91:185S-91S

18. Widmer AF. IV-related infections. In: Wenzel RP, ed. Prevention and Control of Nosocomial Infections. Baltimore: Williams \& Wilkins, 1993:556-79.

19. Pearson ML. Guideline for prevention of intravascular-device-related infections. Hospital Infection Control Practices Advisory Committee. Infect Control Hosp Epidemiol 1996;17:438-73.

20. Sitges-Serra A, Pi-Suner T, Garces JM, Segura M. Pathogenesis and prevention of catheter-related septicemia. Am J Infect Control 1995;23:310-6

21. Widmer AF, Nettleman M, Flint K, Wenzel RP. The clinical impact of culturing central venous catheters. A prospective study. Arch Intern Med 1992;152:1299-302.

22. Ryan JA Jr, Abel RM, Abbott WM, et al. Catheter complications in total parenteral nutrition. A prospective study of 200 consecutive patients. N Engl J Med 1974;290:757-61.

23. Mitchell A, Atkins S, Royle GT, Kettlewell MG. Reduced catheter sepsis and prolonged catheter life using a tunnelled silicone rubber catheter for total parenteral nutrition. Br J Surg 1982;69:420-2. 


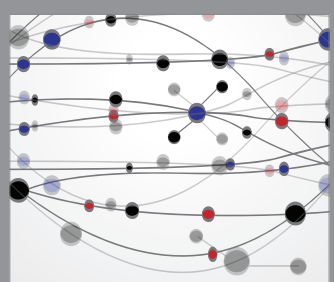

The Scientific World Journal
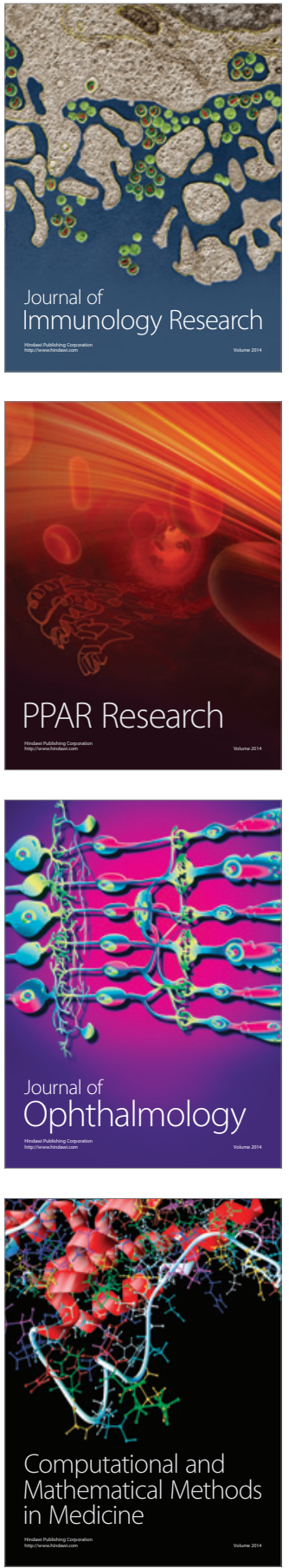

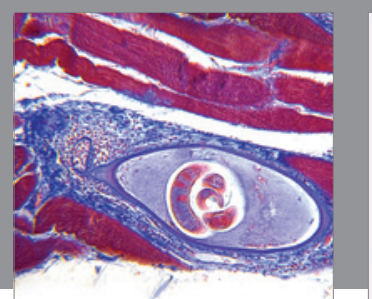

Gastroenterology Research and Practice

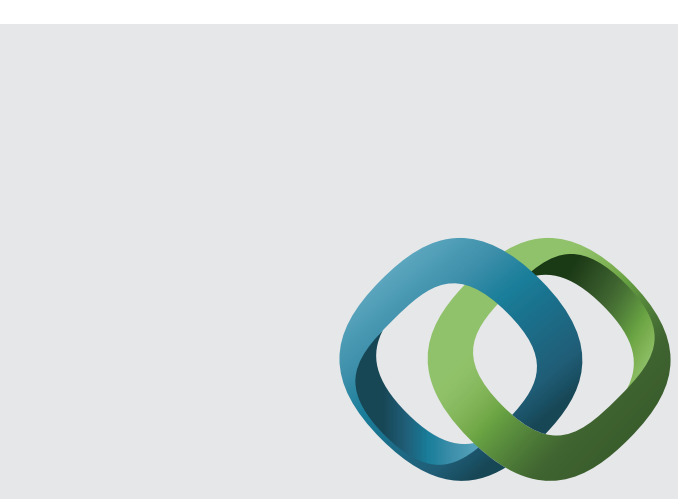

\section{Hindawi}

Submit your manuscripts at

http://www.hindawi.com
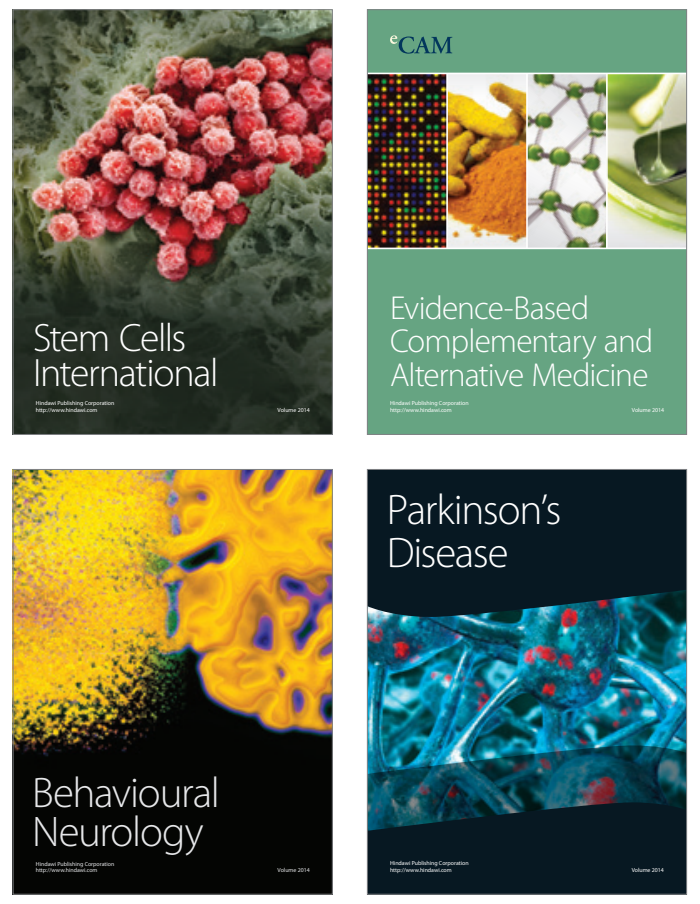
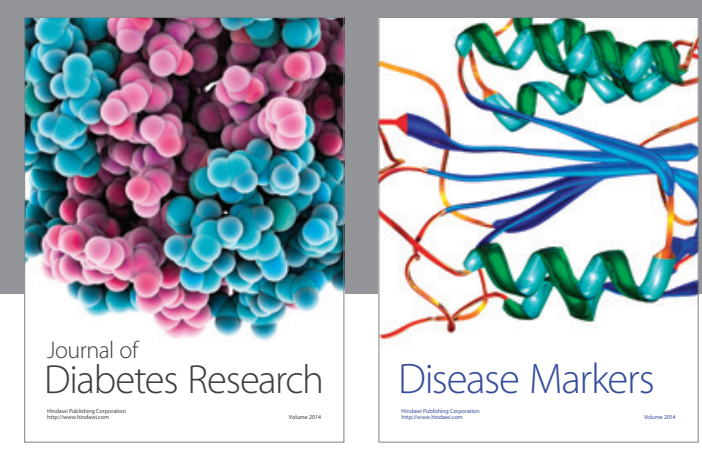

Disease Markers
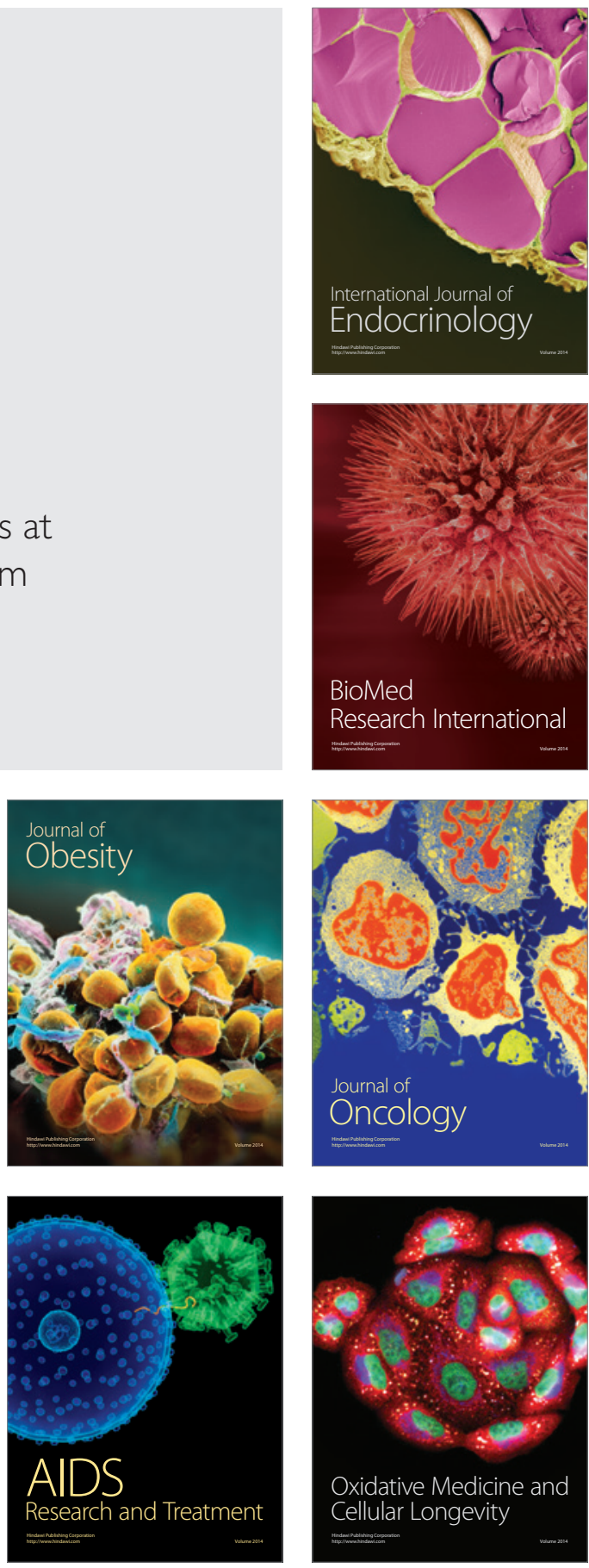